\title{
Concept «teacher» in language consciousness of students of philological faculty
}

\section{[Концепт «учитель» в языковой сознательности студентов филологического факультета]}

\author{
Farida I. Gabidullina - Bolat S. Korganbekov - Venera F. Makarova - Raif \\ A. Zakirov - Gelyusya F. Kayumova
}

DOI: 10.18355/XL.2019.12.03.04

\begin{abstract}
This article is about the representation of concept "teacher" in language consciousness of students in the context of socially important events at the beginning of XXI century. Based on an associative experiment, we concluded the discrepancy of a concept, because many years the treatment of a teacher as an ideal began to change to bad in the last 10 years. Learning the word associations of the students to the word "teacher," the author of the article shows the degree of the importance of personal and professional qualities of the teacher and his social status.
\end{abstract}

Key words: teacher, concept, education, associative experiment

\section{Аннотация}

В центре внимания нашей работы - концепт «учитель». Термин концепт впервые был предложен в начале XX века С.А. Аскольдовым, который обозначал им «мелькающие понятия, мысленные образования, замещающие в процессе мысли множество реальных и представимых предметов одного итого же рода. Отвергнутая тогда, сегодня идея о концептуальном видении мира находит колоссальную популярность. В первую очередь ученых интересуют культурно значимые концепты. Исследование концепта «учитель» в период реформы в образовательной системе имеет особую актуальность.

Ключевые слова: учитель, концепт, обучение, ассоциативный эксперимент

\section{Introduction}

В центре внимания нашей работы - концепт «учитель».Термин концепт впервые был предложен в начале XX века С.А. Аскольдовым, который обозначал им «мелькающие понятия, мысленные образования, замещающие впроцессе мысли множество реальных и представимых предметов одного итого же рода (Askoldov 1997: 267-270). Отвергнутая тогда, сегодня идея о концептуальном видении мира находит колоссальную популярность (Akar, 2016; Baytak et al., 2011; Bochkareva et al., 2017).

В первую очередь ученых интересуют культурно значимые концепты. Исследование концепта «учитель» в период реформы в образовательной системы имеет особую актуальность.

В «Большом толковом словаре русского языка» слово учитель имеет два толкования: 1) «тот, кто преподает какой-либо учебный предмет в школе, преподаватель»; 2) «человек, обладающий высоким авторитетом для кого-либо в какой-либо области, имеющий последователей» (Kuznetcov, 2000: p. 1411). В «Новом объяснительном словаре синонимов» также отмечается два значения слова учитель и подчеркивается, что во втором значении подразумевается «человек, который благодаря своим человеческим качествам, мудрости, таланту

XLinguae, Volume 12, Issue 3, June 2019, ISSN 1337-8384, eISSN 2453-711X 
и т.п. является авторитетом для других людей, которые у него учатся и которые считают себя его учениками и последователями» (Новый объяснительный словарь синонимов русского языка, 2003: 1226; New explanatory dictionary of synonyms of the Russian language, 2003: p. 1226). Данные «Этимологического словаря» показывают, что праславянское слово ис̆іtіродственно с древнепрусским словом iaukint «упражнять», древнеиндийским ucuati «находит удовольствие, имеет обыкновение» (Fasmer, 1987: p. 180).

\section{Methodology}

В данной статье используются сравнительно-исторический и системнотипологический методы в соответствии с перспективой и характером исследования (Magsumov, 2014: 720-721). Основным принципом является систематический и полный анализ исследуемой проблемы.

\section{Results}

Пониманию концепта учитель способствует также изучение истории становления профессии учителя. Следует отметить предельно уважительное отношение к профессии учителя в Древней Руси, их почтительно называют мастерами грамоты. В XIV-XV веках из «мастеров грамоты» начинает формироваться сословие профессиональных учителей, а в XVII веке в России уже предпринимаются серьезные шаги по созданию высшей школы (Mazalova, 2006: 56). Эпоха просвещения вносит свои коррективы в образовательную систему и деятельность учителя. С одной стороны, все более продвигаются идеи западной образовательной системы, с другой стороны - начинается поиск уникальных самобытных сторон русской педагогики (Magsumov, 2015). В этот же период начинается становление элитарного образования, которое успешно развивается вплоть до революции и считается качественным как в образовательном, так и в воспитательном планах (Magsumov, 2013: 84). Такими передовыми учебными заведениями являлись Императорский лицей, Нежинское высших наук училище, Пажеский Его Императорского Величества корпус, Московский благородный пансион, Смольный институт благородных девиц, Павловский институт в Петербурге. Учителя данных учебных заведений не только транслировали знания, но и были главными воспитателями.В драматичных, часто противоречивых условиях ведет профессиональную деятельность учитель XX века. Правдиво описана первая половина этой эпохи в статье Ф.Габидуллиной: «первая половина XX века была насыщена многообразными историческими событиями во внутренней и внешней политике первой в мире социалистической страны. Экономический кризис конца 20-х начала 30-х годов. Это было самое трудное время в жизни Советской России, когда она, после шести лет войны и социальных катаклизмов находилась во мгле» (Gabidullina, F.I., 2013:502). Однако нельзя не отметить, что статус учителя для подрастающего поколения в это время был достаточно велик. Учитель являлся не только наставником, дающим знания, но и духовным ориентиром, пропагандистом, примером для подражания. 
Лишь в 90-е годы XX века, в эпоху, когда страна погрузилась в экономический и духовно-нравственный кризис, статус учителя опускается очень низко. В настоящее время идет процесс реформирования образовательной системы, внедряются механизмы обеспечения качества образования, однако отклик 90-х находит отражение в отношении к учителю.

Современный педагог - это не просто учитель-предметник, транслирующий знания и формирующий умения, но и учитель-воспитатель, способный организовать целенаправленное управление процессом воспитания и развития личности ребенка на основе гуманистических традиций. Поэтому в данной работе личность педагога в первую очередь будет рассматриваться как транслятор духовно-нравственных качеств, как личность, способствующая формированию у учащихся таких качеств, как самостоятельность, способность к сотрудничеству, мобильность, динамизм, ответственность за судьбу страны, так как именно такие качества, по мнению исследователей, являются востребованными в современном обществе и предъявляются к учителюноватору (Vinnichenko, 2005: 4).

Профессия учителя имеет ряд особенностей, которые предъявляют особые требования к личности педагога. Таковыми являются:

1) постоянный самоконтроль, постоянное напряжение внимания. Как известно, ученический состав имеет тенденцию меняться, а каждый новый состав имеет свои особенности, что обуславливает необходимость самоконтроля, внимания.

2) педагогический такт и понимание интересов учащихся. Педагогический такт выражается в умении найти оптимальные меры воспитательного воздействия в различных ситуациях. Критерием оптимальности называют отсутствие явного и скрытого сопротивления воспитанию.

3) наблюдательность. Именно это качество помогает учителю в достижении хороших результатов и в обучении, и в воспитании. Именно наблюдательность помогает сочетать индивидуальную и фронтальную работу; слушать, оценивать ответ ученика и одновременно держать в поле зрения весь класс; объяснять новый материал и одновременно поддерживать активность класса; обеспечить равноправное распределение обязанностей при выполнении группового проекта.

4) высокая культура речи. Речь педагога является примером для учащихся, поэтому он должен стремиться к ее правильности, краткости, простоте, ясности, точности, выразительности, эмоциональности. Кроме этого, профессия педагога подразумевает необходимость обращать внимание на смысловое содержание высказывание. Подбирая слова, учитель опирается на индивидуальные и возрастные особенности учеников, заботясь о том, чтобы слова и выражения были понятными и было бы возможным построить диалог на уроке или во внеурочное время. Во время внеклассных мероприятий, бесед уместно иногда использовать юмор, не забывая при этом сохранять тактичность. 
5) умение разнообразить учебный материал, формы и способы воспитательной работы. Считается, что использование разнообразных приемов, методов работы полезно в первую очередь для учащихся, так как способствует концентрации внимания, активизации познавательной деятельности, эффективности воспитательных работ. В то же время ученые замечают, что это полезно и для личности учителя не только в плане профессионального развития, но и сохранения здоровья. «Учитель, как правило, имеет дело с одним и тем же многократно повторяющимся учебным материалом. С возрастом компенсаторные возможности организма снижаются, что может привести к функциональным неврозам», - замечает К.Левитан (Levitan, 1993: 58).

Кроме того, существуют определенные моральные нормы, которые из требований извне превращаются в собственные убеждения эффективно работающих педагогов. Остановимся кратко на них:

- знание и добросовестное выполнение своих профессиональных обязанностей.

- профессиональная увлеченность. Данное качество предполагает полную самоотдачу учителя при выполнении профессиональных обязанностей.

- профессиональное мастерство. Важность этого качества обусловлено тем, что его отсутствие снижает уровень образованности детей, препятствует ускоренному внедрению инновационных методов и технологий.

- забота о благе своих учеников. Забота о благе каждого отдельного ученика является одним из основных требований к педагогу. В каждом отдельном случае это благо может выражаться по-разному, что определяется учителем исходя из положения ученика в классе, семье, взаимоотношения с одноклассниками и взрослыми и т.д. Забота о благе учеников выражается как минимум в четырех аспектах: забота о физическом, интеллектуальном, нравственном и духовном развитии учеников. В современных трудах эти и некоторые другие аспекты характеризуются как составляющие педагогическую культуру педагога. В настоящее время это качество приобретает все большую актуальность, так как учителя, согласно «профессиональному стандарту педагога, должны проявлять готовность принять разных детей, вне зависимости от их реальных учебных возможностей, особенностей в поведении, состояния психического и физического здоровья» [Professional Standard for Teachers Профессиональный стандарт педагога].

Забота о физическом здоровье учащихся становится все более значимой проблемой, так как в школу уже приходят большое количество детей с теми или иными отклонениями в здоровье, в психике, а на протяжении учебы ситуация только усугубляется. В настоящее время многие проблемы, связанные с утомляемостью, с излишней загруженностью обучающихся остаются нерешенными. Однако в последние несколько лет ведутся актуальные поиски решения проблем по охране здоровья учащихся, внедряются здоровьесберегающие технологии. Забота о сохранении здоровья учащихся может проводиться в следующих направлениях: профилактика стрессовых ситуаций, профилактика вредных привычек, формирование основ правильного питания, развитие двигательной активности и т.д. 
Забота об интеллектуальном развитии учеников является одной из главных задач учителя. Существует определенный минимум знаний и умений, которыми должен овладеть ученик (Gabidullina, 2013; Aydarova et al, 2017; Korableva et al., 2019; Magmusov, 2013; Korkmaz and Avci, 2016; Thalassinos et al., 2011).

Как занижение, так и завышение этого минимума может привести к тому, что у учащихся сформируется более низкий, чем ожидается уровень знаний. Однако следует помнить о том, что степень успеваемости учащихся по разным предметам может быть разной, индивидуально-дифференцированный подход в обучении подразумевает варьирование заданий, методов работы, степень оказываемой учителем помощи при решении задач, исходя из особенностей учащихся (Günel \& Pehlivan, 2015; Mathews, 2016; Byker \& Marquardt, 2016; Husnutdinov et al., 2016 b; Kilınç et al., 2016; Mauch \& Tarman, 2016; Grammes and Açıkalın, 2016).

Забота о нравственном воспитании учащихся обязывает учителя содействовать формированию тех качеств у своих воспитанников, которые необходимы человеку для морального образа жизни.

Забота о духовном воспитании учащихся тесно связана с предыдущей задачей. В современной педагогике и реальной педагогической практике должна активно решаться задача формирования духовно-нравственной культуры школьников, которая является фундаментальной основой общего образования, базой для самосовершенствования личности и социального взаимодействия на основе единства свободы и ответственности (Mazalova, 2006; Husnutdinov et al., 2016 a; Tarman and Kuran, 2015; Tarman and Yigit, 2013; Tünkler et al., 2016). Опыт освоения духовно-нравственных смыслов и ценностей культуры позволит решить одну из самых актуальных задач современной общеобразовательной школы - побудить человека к развитию и самосовершенствованию на основе различения добра и зла, помочь ему выработать ориентиры нравственной оценки, как своих действий, так и всех сторон общественных отношений (Gabidullina, 2015: 201).

Кроме того, стоит процитировать К.Левитана: «конечно, можно быть хорошим учителем, обладая различными чертами характера. Однако следующие качества, как свидетельствует практика, имеют существенное значение для успешной профессиональной деятельности и прогрессивного развития личности учителя. Это любовь, доброжелательность к детям, самодисциплина, терпение, оптимизм, отзывчивость, бодрость и живость» (Levitan, 1993: 76). О.Василенко также подчеркивает, что высокий моральный облик является необходимым качеством личности педагога, так как он ежедневно дает уроки нравственности своим воспитанникам. «Следовательно, - пишет ученый, - циник, морально нечистоплотный человек не должен быть педагогом» (Vasilenko, 2016: 156).

Отдельного внимания заслуживает видение личностных и профессионально значимых качеств студентами - будущими педагогами. 
Нельзя сказать, что личность учителя не исследована учеными вообще, однако стремительно меняющиеся реалии, в том числе реалии жизни школьного пространства, обуславливают изменения в языковой картине мира. Молодежь в силу психофизиологических факторов, более чувствительна к подобным трансформациям, поэтому в данной статье исследуется особенности репрезентации концепта «учитель» в языковом сознании студентов филологического факультета Елабужского института КФУ. Благодаря данному эксперименту представляется возможность увидеть наиболее и наименее значимые качества личности учителя глазами современного поколения.

Всего в экспериментальной работе участвовало 30 студентов - будущих учителей, то есть те реципиенты, чья деятельность в будущем напрямую должна будет связана с педагогической деятельностью. Нами был использован прием ассоциативного эксперимента, который является направленным на выявление ассоциаций, сложившихся у индивида в его предшествующем опыте (Kenna, \& Russell, 2015; Waters \& Russell, 2016; Magmusov, 2017; Alajmi, 2019; Volchik and Maslyukova, 2019). Мы использовали лишь один вид ассоциативного эксперимента, так называемый «свободный ассоциативный эксперимент», при проведении которого испытуемому предлагают ответить словом А - первым пришедшим в голову при предъявлении слова Б, ничем не ограничивая ни формальные, ни семантические особенности слова А.

Bсе ответы реципиентов можно разделить на четыре группы: ассоциаты, связанные с профессиональной деятельностью; личностные ассоциаты; социально окрашенные ассоциаты и образные ассоциаты. Количественная характеристика ассоциатов каждой из групп имеет отличия. В ниже приведенной диаграмме наглядно продемонстрированы количественные характеристики ассоциатов разных групп (рисунок 1).

Основной Оссоциаты
$=$ Овязанные с профессиональной деятельностью
$=$ образные
$=$ социально окрашенные
$=$-личностные

Рис. 1. Ассоциаты на слово-стимул «учитель» у студентов филологического факультета (количественная характеристика)

Среди ассоциатов, связанных с педагогической деятельностью, были даны такие ответы-реакции на слово-стимул «учитель»:знание, ЕГЭ, школьная доска,

XLinguae, Volume 12, Issue 3, June 2019, ISSN 1337-8384, eISSN 2453-711X 
методика, инновационные технологии, ставит оценки, технологическая карта урока, открытый урок, педсовет. Всего такие ответы были даны пятнадцатью студентами, что составляет 50\% всех реципиентов .Вторыми по количеству слов-реакций оказались образные ассоциаты. Восемь студентов, то есть 27\% реципиентов на слово-стимул ответили словами «хранитель знаний», «строитель» (личности), «мученик», «как ангел» (имелось ввиду человек с ангельской выдержкой), «крепость», «писатель судеб». Социальные ассоциаты были озвучены четырьмя студентами, то есть $13 \%$ реципиентами. Среди ответов были озвучены такие слова-реакции как «без прав, но с обязанностями», «увеличили зарплату», «участвует на выборах». Сравнительно небольшое количество социальных ассоциатов, видимо, объясняется тем, что времена, когда статус учителя колебался между идеалом и социально и материально незащищенной личностью, прошли. Современный учитель имеет возможность развиваться профессионально, имеет сравнительно неплохое материальное обеспечение, следовательно, проблема его статуса начинает терять свою актуальность.

Наименьшее количество слов-реакций можно назвать личностными ассоциатами. Всего три студента, то есть 10\% реципиентов назвали словареакции «добрый», «строгий», «терпеливый». Как нам представляется, данный результат отражает реальное положение дел: общество требует от учителя высоких профессиональных показателей, требования столь высоки, что возникают ассоциации «учитель-крепость», «учитель - писатель судеб», социальное положение учителя перестало восприниматься как проблема, требующая каких-либо серьезных вмешательств, а учитель сам перестал восприниматься как личность, только как профессионал.

Слова-ассоциаты на слово-стимул «учитель» позволяют создать следующий языковой портрет учителя начала XXI века: профессионал, увлеченный своей деятельностью; активно внедряющий передовые технологии в образовательное пространство; его деятельность важна для становления личности обучающихся и играет значительную роль в их судьбе; имеет достаточно устойчивый социальный статус; обладает некоторыми положительными личностными качествами.

\section{Conclusions}

Таким образом, результаты свободного ассоциативного эксперимента показали, что студенты филологического факультета первостепенным для учителя считают обладание профессиональными качествами, при этом большая часть слов-реакций касалась реформ в образовательной сфере: введение ЕГЭ, внедрение инновационных методик в процесс обучения. Образные ассоциаты были представлены метафорами и сравнениями, в которых подчеркивались терпение, выдержка, свойственные учителям, а их деятельность сравнивалась со строительством здания и заложением прочного фундамента и даже с божественным началом, имеющим силу влиять на судьбу человека.

В меньшей мере студентов интересует социальный статус учителя и, что с одной стороны, неожиданно, с другой - объяснимо в условиях сегодняшних реалий, наименьшую заинтересованность вызывает учитель-личность. Более того, отражение концепта «учитель» в языковом сознании студентов уже готовит их к тому, что работа учителя - это призвание и образ жизни, и проблемы личностного характера при выборе данной профессии будут отходить на второй план. В целом, восприятие личности педагога у будущих учителей адекватно и во многом соответствует требованиям, предъявляемым к представителям данной профессии.

XLinguae, Volume 12, Issue 3, June 2019, ISSN 1337-8384, eISSN 2453-711X 


\section{Acknowledgements}

The work is performed according to the Russian Government Program of Competitive Growth of Kazan Federal University.

\section{Bibliographic references}

AKAR, C. 2016. Investigating the students' perceptions of the democratic values of academicians. Journal of Social Studies Education Research, vol. 7(1), pp. 96-139. doi:10.17499/jsser.49601

AYDAROVA S. H. - GINIYATULLINA L. M. - SAGDIEVA R. K. HUSNUTDINOV D. H. - MIRZAGITOV R.H. - GABIDULLINA F.I. 2017. Models of media education in teaching Tatar language. Espacios, vol. 38 (60).

ALAJMI, M. A. 2019. The impact of E-portfolio use on the development of professional standards and life skills of students in the Faculty of Education at Princess NouraBint Abdul Rahman University, Entrepreneurship and Sustainability, vol. 6(4) pp. 1714-1735. doi.org/10.9770/jesi.2019.6.4(12)

ASKOLDOV S.A. 1997. Concept and the word. Russian literature: from the theory of literature to the theory of text. Under the editorship of V. N. Neroznak. M.: Academia, pp. $267-279$.

BAYTAK, A. - TARMAN, B. - AYAS, C. 2011. Experiencing technology integration in education: Children's perceptions. International Electronic Journal of Elementary Education, vol. 3(2), pp. 139-151.

BOCHKAREVA, T. N. - AKHMETSHIN, E. M. - KOROTKOVA, A. L. LYITKINA, N. L. - NASIPOV, I. S. - KHALIULLINA, A. G. 2017. Research of students' cognitive activity. Espacios, 38(60)

BYKER, E. J. - MARQUARDT, S. K. 2016. Using critical cosmopolitanism to globally situate: Multicultural education in teacher preparation courses. Journal of Social Studies Education Research, vol. 7(2), pp. 30-50.

FASMER M. 1987. Etymological dictionary of the Russian language. In four volumes: T. IV: T - Yaschur. Translation from Germany and additional O.N. Trubacheva. In: Progress, 1987, 864 pp.

GABIDULLINA F.I. 2013. Religious motives in the work of Sagit Sunchalay and Anna Akhmatova. International Congress on Interdisciplinary Behavior and Social Science. 2013, Indonesia, pp. 500-504.

GÜNEL, E. - PEHLIVAN, A. 2015. Examining the citizenship and democracy education textbook and curriculum in terms of global education. [Küresel eğitim çerçevesinde vatandaşlık ve demokrasi eğitimi ders kitabı ve öğretim programı] Journal of Social Studies Education Research, vol. 6(1), pp. 123-171. doi:10.17499/jsser.88468s

GRAMMES, T. - AÇIKALIN, M. 2016. Qualitative data collection and interpretation: A turkish social studies lesson. [Nitel veri toplama ve yorumlama: Türkiye'den bir sosyal bilgiler dersi] Journal of Social Studies Education Research, vol. 7(1), pp. 1-40. doi:10.17499/jsser.47392

HUSNUTDINOV, D.H. - SAGDIEVA, R.K. - MIRZAGITOV, R.H. 2016a. Comparative constructions in G. Ibragimov's works. Journal of Language and Literature. 2016. vol. 7, issue 4, pp. 42-45.

HUSNUTDINOV, D.H. - YUSUPOVA, Z.F. - SHAKUROVA, M.M. - YUSUPOV, A.F. - MIRZAGITOV, R.H. 2016b. Practical aspect of comparative research on the material of the Russian and Tatar languages: XIX-XXI centuries. Journal of Language and Literature. vol.7, issue.2, pp.191-194.

KENNA, J. L. - RUSSELL, W. B. 2015. Secondary social studies teachers' time commitment when addressing the common core state standards. Journal of Social Studies Education Research, vol. 6(1), pp. 26-48. doi:10.17499/jsser.37219

XLinguae, Volume 12, Issue 3, June 2019, ISSN 1337-8384, eISSN 2453-711X 
KORABLEVA, O. - DURAND, T. - KALIMULLINA, O. - STEPANOVA, I. 2019. Studying user satisfaction with the MOOC platform interfaces using the example of coursera and open education platforms. Paper presented at the ACM International Conference Proceeding Series, pp. 26-30. doi:10.1145/3322134.3322139

KORKMAZ, U. - AVCI, Z. Y. 2016. Turkish pre-service teachers' experiences with contemporary technology games and perceptions about teaching with instructional games. Research in Social Sciences and Technology, 1(1)

KILINÇ, E. - KILINÇ, S. - KAYA, M. M. - BAŞER, E. H. - TÜRKÜRESIN, H. E. - KESTEN, A. 2016. Teachers' attitudes toward the use of technology in social studies teaching. Research in Social Sciences and Technology, vol. 1(1), pp. 59-76.

KUZNETCOV S.A. 2000. Big explanatory dictionary of Russian language. SPb.: Norint, $1536 \mathrm{p}$.

MAGMUSOV, T.A. 2013. School and children during the celebrations of the 300th anniversary of the romanov dynasty. Bylye Gody. (4) 30, pp. 79-87.

MAGSUMOV, T.A. 2017. Family and school in Russia at the beginning of the 20th century: Attempts to bridge the gap. European Journal of Contemporary Education. vol. 6 (4), pp. 837-846. DOI: 10.13187/ejced.2017.4.837

MATHEWS, S. A. 2016. Using digital participatory research to foster glocal competence: Constructing multimedia projects as a form of global and civic citizenship. Journal of Social Studies Education Research, vol. 7(2), pp. 1-29.

MAUCH, J. - TARMAN, B. 2016. A historical approach to social studies laboratory method. Research in Social Sciences and Technology, vol. 1(2), pp. 55-66.

MAZALOVA M.A. 2006. The History of pedagogic and education. M.: High education, 2006. 192 pp.

NEW EXPLANATORY DICTIONARY OF SYNONYMS OF RUSSIAN LANGUAGE. Under total hands. Akadem. Y. D. Apresian. M.: School «Languages of Slavic culture», 2003. 1448 pp.

RUSSIA. BIG ENCYCLOPAEDIC DICTIONARY. 2000 realities of history, culture, life. Under the General editorship of Y. E. Prokhorov. M.: AST-PRESS BOOK, 2007, $736 \mathrm{p}$.

THALASSINOS, I.E. - STAMATOPOULOS, V.T. - ARVANITIS, E.S. 2011. Gender wage gap: Evidence from the Hellenic maritime sector 1995-2002. European Research Studies Journal, vol. 14(1), pp. 91-101

TARMAN, B. - KURAN, B. 2015. Examination of the cognitive level of questions in social studies textbooks and the views of teachers based on bloom taxonomy. Kuram Ve Uygulamada Egitim Bilimleri, vol. 15(1), pp. 213-222, 10.12738/estp.2015.1.2625 TÜNKLER, V. - TARMAN, B. - GUVEN, C. 2016. A metaphorical approach regarding the equipment of students with abstract concepts and values included in the citizenship and democracy education curriculum. Egitim Ve Bilim, vol. 41(185), pp. 123-145

VOLCHIK, V. - MASLYUKOVA, E. 2019. Trust and development of education and science, Entrepreneurship and Sustainability Issues 6(3), pp. 1244-1255. http://doi.org/10.9770/jesi.2019.6.3(27)

YIGIT, M. F. 2017. Value priorities of public and private university students. Research in Social Sciences and Technology, vol. 2(1)

ZARECHNEVA E.N. 2009. Socio-cultural concept of "teacher": cognitive-discursive study of: abstract of thesis, PhD thesis, philological sciences. Barnaul, $20 \mathrm{pp}$

WATERS, S. - RUSSELL, W. B. 2016. Virtually ready? pre-service teachers' perceptions of a virtual internship experience. Research in Social Sciences and Technology, 1(1)

Words: 3318

Characters: 26372 (14,65 standard pages)

XLinguae, Volume 12, Issue 3, June 2019, ISSN 1337-8384, eISSN 2453-711X 
Farida I. Gabidullina

Yelabuzhsky Institute of Kazan (Privolzhsky) Federal University

Tatarstan,

Russia

farida-vip@mail.ru

Bolat S. Korganbekov

Eurasian National University named after L.N.Gumilyov.

Kazakhstan,

bolat64@mail.ru

Venera F. Makarova

Naberezhnye Chelny State Pedagogical University

Tatarstan,

Russia

makarova_vf@mail.ru

Raif A. Zakirov

Naberezhnye Chelny state pedagogical University

Tatarstan,

Russia

razina.mh@mail.ru

Gelyusya F. Kayumova

Kazan (Privolzhsky) Federal University

Tatarstan,

Russia

gulfar21@mail.ru 